\title{
Development and validation of a brief self- assessed wisdom scale
}

\author{
Sai-fu Fung, Esther Oi-wah Chow ${ }^{*}$ (D) and Chau-kiu Cheung
}

\begin{abstract}
Background: This longitudinal study aimed to develop a nine-item Brief Self-Assessed Wisdom Scale (BSAWS) derived from the original 40-item Self-Assessed Wisdom Scale (SAWS).

Methods: The psychometric properties of the shortened scale were evaluated based on a sample of 157 older adults. The factor structure and dimensionality of the original SAWS were examined using confirmatory factor analysis. Subsequent explorative factor analysis of the BSAWS supported the construct validity of the shortened scale.

Results: The internal consistency, convergent validity and construct validity of the shortened scale were also evaluated and the results indicated that the BSAWS possesses good psychometric properties and is comparable with the full version.

Conclusions: This scale refinement may help researchers and practitioners conduct epistemological surveys or clinical research related to wisdom.
\end{abstract}

Keywords: Wisdom, SAWS, BSAWS, Confirmatory factor analysis, Older adults

\section{Background}

Wisdom is an ancient construct with a long history of conceptualisation based on normative approaches across cultures, ranging from Greek philosophers such as Socrates and Aristotle to Chinese philosophers such as Confucius. In recent years, the concept of wisdom has been further revitalised in empirical research on social and positive psychology [1-4]. The latest empirical research on wisdom can be broadly categorised into two domains [5]. The first one is performance measure of personal wisdom, also known as Berlin wisdom paradigm, involves the analysis of wisdom-related performance in laboratory setting with trained raters to transcribe the responded data introduced in the 1980s $[6,7]$. In recent years, this explicit theory based method was utilised and adapted in different contexts, such as in Australia [8], China [9], Germany [10] and United States [11]. The focus of this paper is the second approach, i.e., latent factor analyses of wisdom that mainly rely on using self-reported survey methods to assess wisdom,

\footnotetext{
* Correspondence: esther.chow.ss@cityu.edu.hk

Department of Social and Behavioural Sciences, City University of Hong Kong, Kowloon Tong, Hong Kong, China
}

such as Self-Assessed Wisdom Scale (SAWS) [2], Threedimensional Wisdom Scale [12], Practical Wisdom Scale and Transcendent Wisdom Scale [13] and Wisdom Development Scale [14], etc. We acknowledge that the above constructs indeed provide important tools for researchers and practitioners to study the issues related to different facets of wisdom. The purpose of this study is not to compare the wisdom constructs, which have been widely discussed and debated by scholars, both normatively and with empirical evidence [3, 15-20]. Rather, we embrace the idea that each wisdom construct has its own merits and the variety of constructs can enhance our understanding of wisdom across different dimensions and situations.

Nevertheless, the abovementioned latent factor analyses of wisdom constructs suffer from two limitations. First, the scale developers did not employ the latest validation tools to evaluate the dimensionality and factor structure of the scales. These scales were developed with a sole reliance on the exploratory factor analysis (EFA) results to identify the factor structure, without verification by a confirmative factor analysis (CFA) [2, 13]. Second, while some studies have attempted to validate the

(c) The Author(s). 2020 Open Access This article is distributed under the terms of the Creative Commons Attribution 4.0 International License (http://creativecommons.org/licenses/by/4.0/), which permits unrestricted use, distribution, and reproduction in any medium, provided you give appropriate credit to the original author(s) and the source, provide a link to the Creative Commons license, and indicate if changes were made. The Creative Commons Public Domain Dedication waiver (http://creativecommons.org/publicdomain/zero/1.0/) applies to the data made available in this article, unless otherwise stated. 
wisdom scales with a CFA, the adopted cut-off criteria were far below the current standards, and the scales also suffer from problems like a lack of internal reliability [2, $5,12,21,22]$. To solve the above problems, many wisdom scales have been revised, validated and adapted into different languages or developed into shortened versions for ease of use [12, 17-19, 23-26]. Yet, there is paucity of study examined the dimensionality and validity of SAWS with the latest psychometric tools which warrant our attention.

The Self-Assessed Wisdom Scale (SAWS), a selfreported instrument for measuring wisdom at the individual level, has been widely used by researchers and clinical practitioners. SAWS focuses on five dimensions, namely experience, reminiscence, openness, emotion regulation and humour, and has received positive evaluations of its internal consistency and psychometric properties [2, 18, 19, 23, 27]. Numerous studies have used SAWS to explore the relationships between wisdom and various psychosocial outcomes. JD Webster [28] suggested that wisdom is positively associated with psychosocial characteristics derived from the Erikson tradition, such as ego-integrity, life attitudes and values. Using hierarchical regression analysis, JD Webster, GJ Westerhof and ET Bohlmeijer [29] identified a positive relationship between wisdom and mental health among Dutch adults. The balanced time perspective also uniquely predicted both mental health and wisdom in a sample of 512 adults in the Netherlands [30]. JD Webster and XC Deng [31] used the wisdom scale to study the relationship between traumatic life events and mental health outcomes among 320 respondents in Canada. A later study further suggested that wisdom and meaning contribute to positive self-development in areas such as optimism, self-esteem and self-characteristics in emerging adulthood [27]. In a recent study, C Cheung and EO Chow [32] identified a positive relationship between wisdom and well-being among older Chinese.

Despite the widespread application of SAWS, few studies have managed to fully replicate its original factor structure. Although SAWS possesses good internal consistency and convergent validity [23, 27], its factor structure and dimensionality are inconclusive and subject to a number of limitations $[17,19]$. First, to date, no studies have used CFA to validate the 40-item five latent factor structure of the scale. JD Webster [23] used CFA to analyse five sub-scale factors used to predict the latent construct wisdom rather than analysing all of the 40 items. Second, some of the SAWS items have a complicated factor structure. For example, JD Webster [2] reported that the 'humor and openness dimensions have some overlap and weaker loadings' (p. 16). In particular, items 12, 27 and 17 share the attributes of emotion regulation and reminiscence, items 14 and 24 are related to both emotion regulation and humour and items 5 and 20 are related to openness and humour.

The cross-cultural differences in wisdom that may also account for studies unable to replicate the factor structure. Controversies have arisen when studies have attempted to adapt the scale to other contexts. P Alves, L Morgado and Bd Oliveira [33] attempted to validate a Portuguese version of the 40-item SAWS, but their EFA results showed that the factor structure was significantly different from that of the original scale. In response, the authors proposed five alternative wisdom domains, namely reflection, mood, emotional self-regulation, experience and open mindedness, which are significantly different from those of the original SAWS. Due to the mixed findings on the factor structure of the wisdom scale, A Urrutia, GM de Espanes, C Ferrari, G Borgna, AM Alderete and F Villar [34] combined the 40-item SAWS and 79-item Wisdom Development Scale (WDS) to obtain a shortened 20-item scale with a three-factor structure for studying wisdom related issues. They applied the shortened scale in a study based on a sample of older adults in Argentina. However, their CFA results suggested very marginal model fit.

Given the controversies surrounding the full version of SAWS, this study explores whether the factor structure and dimensionality of the scale need further refinement. As JD Webster [2], who developed the original scale, stated, 'continued refinement of specific scale items may eliminate those which explain little overall variance' (p. 21). The first part of this study shows that the full 40item scale fails to replicate the factor structure of SAWS using CFA. However, the EFA results support the development of a unidimensional nine-item Brief SelfAssessed Wisdom Scale (BSAWS). In the next section, the psychometric properties of the newly proposed BSAWS are evaluated and various tools are used to examine its internal consistency, convergent validity and construct validity. Overall, the results show that the BSAWS provides an efficient and valid tool for assessing wisdom using empirical data and psychometric evidence in different cultural contexts, i.e., Chinese culture.

\section{Methods \\ Participants}

This study used a longitudinal repeated measures design with 157 community-dwelling older adults from older adult service centres in Hong Kong [35-37]. According to Table 1 , the respondents were aged 72.8 years on average $(\mathrm{SD}=8.55)$ and participated in the study on a voluntary basis. For the inclusion criteria, the respondents possessed sufficient cognitive ability (with 7.9 years of education on average) to understand and respond to the self-reported questionnaire as well as have capacity to provide consent for participation in this study. The 
Table 1 Participant demographic characteristics

\begin{tabular}{ll}
\hline Variable & Respondents $(\mathrm{n}=157)$ \\
\hline Age mean (SD) & $72.8(8.55)$ \\
Gender $n(\%)$ & $40(25.5 \%)$ \\
Male & $117(74.5 \%)$ \\
Female & \\
Education level $n$ (\%) & $26(16.6 \%)$ \\
No formal education & $50(31.8 \%)$ \\
Primary education & $45(28.7 \%)$ \\
Secondary education & $30(19.1 \%)$ \\
Tertiary education & $6(3.8 \%)$ \\
Missing & \\
Martial status n (\%) & $15(9.6 \%)$ \\
Single & $64(40.8 \%)$ \\
Married & $15(9.6 \%)$ \\
Divorce/separated & $62(39.5 \%)$ \\
Widowed & $1(0.6 \%)$ \\
Other &
\end{tabular}

sample comprised $25.5 \%$ male and $74.5 \%$ female respondents. There were four waves of data collection: the initial study (study $1 ; n=157$ ) was conducted in June 2016. The respondents then completed the questionnaire again after one (study $2 ; n=136$ ), two (study $3 ; n=135$ ) and eight (study $4 ; n=98$ ) months. The research team strictly adhered to the relevant ethical standards and the project was approved by the university's research ethics committee.

\section{Measurement}

The latest SAWS comprises 40 items that measure five dimensions: emotion regulation (items 32, 2, 22, 12, 27, $7,14,24$ and 17), reminiscence (items $12,27,17,8,28$, $23,13,18,3$ and 33), openness (items $35,25,30,38,5$, 20 and 34), experience (items 26, 6, 16, 21 and 1) and humour (items 14, 24, 5, 20, 39, 19, 29, 4, 9 and 10). The respondents were asked to indicate their level of agreement on a Likert-type scale ranging from $1=$ strongly disagree to $6=$ strongly agree $[2,18,23]$.

\section{Procedure}

The interviewers administered the questionnaire to the respondents at 13 older adult service centres located in different districts in Hong Kong. The items were translated into Chinese using the back-translation procedure [38]. The research team was recruited translator to translate the scale from English to Chinese and then back translated from Chinese to English by the other translator. The back translated version has been verified by the original SAW scale developer JD Webster to confirmed its semantic and conceptual equivalency and avoided any potential cross-cultural biases [39, 40].

CFA was used to replicate and evaluate the construct validity of the SAWS and BSAWS [41-43]. The CFA estimator used diagonally weighted least squares (DWLS) due to the ordinal nature of the Likert scale. DWLS is regarded as less biased and a more optimal fit for this type of scale [44-49]. The results for the following criteria indicated adequate model fit: CFI $>0.95$, TLI $>0.95$, RMSEA $<0.08$, SRMR $<0.08$ [41, 50-52]. In addition to these measures, $\mathrm{X}^{2} / \mathrm{df} \leq 3$ can be used to determine acceptable model fit [53-56].

Factor analysis with the principal component estimation method was used to evaluate the dimensionality and factor structure of the BSAWS [2, 33, 50, 57]. The Kaiser-Meyer-Olkin (KMO) and Bartlett's tests of sphericity were used to evaluate the model. The KMO estimates were over 0.70 and the Bartlett's test was significant $(p<0.01)$, thus confirming that the model had a satisfactory factor structure [58].

In addition, various psychometric testing tools and validated instruments were used to examine the newly proposed BSAWS. The internal consistency of the scale was assessed using Cronbach's alpha [59] and by examining the corrected item-total correlation between the nine items $[50,60]$.

The convergent validity was evaluated using other validation constructs reported in the literature on latent factor analyses of wisdom. The wisdom construct was reported to be significantly positively correlated with well-being, self-esteem and other wisdom measures [5, 61-65]. Hence, this study used the following wellestablished scales to evaluate the convergent validity of the BSAWS: the Personal Well-being Index (PWI) [66, 67], Rosenberg self-esteem (RSE) scale [68-73] and dimensions of the WDS [5, 21]. Research also suggests that wisdom is negatively correlated with depression symptoms [2, 74, 75]. Hence, we used the Geriatric Depression Scale (GDS) [76-78] to evaluate the relationship between depression and the two wisdom scales. The above analysis was implemented using IBM SPSS 25.0 and the $R$ (3.6.0) computing software with lavaan package 0.6-3 [79].

\section{Results}

Table 2 shows the CFA results for the original SAWS and variations of the factor structure in the literature $[2,23,33]$. The CFA results based on study $1(n=157)$ suggested that the original full version of SAWS (Model 1) failed to fit the model, with $\chi^{2}(1570.703) / 510=$ 3.08, $p<0.001$, SRMR $=0.121, \mathrm{CFI}=0.887, \mathrm{TLI}=0.876$ and RMSEA $=0.126$. Similarly, Model 2 failed to fulfil the cut-off criteria for good model fit, as $X^{2}$ (2135.089) / 
Table 2 Confirmatory factor analysis of SAWS and BSAWS

\begin{tabular}{llllllll}
\hline Model & $X^{2}$ & Df & $X^{2} / \mathrm{df}$ & RMSEA [90\% CI] & CFI & TLI & SRMR \\
\hline 1. Webster et al. (2007) & 1570.703 & 510 & 3.08 & $0.126[0.119-0.133]$ & 0.887 & 0.876 & 0.121 \\
2. Alves et al. (2014) & 2135.089 & 692 & 3.09 & $0.126[0.120-0.132]$ & 0.885 & 0.877 & 0.119 \\
\hline
\end{tabular}

$692=3.09, p<0.001, \mathrm{SRMR}=0.119, \mathrm{CFI}=0.885, \mathrm{TLI}=$ 0.877 and $\mathrm{RMSEA}=0.126$.

With reference to the literature on SAWS [2, 23, 33] and the EFA results in Table 3, this study proposes a nine-item BSAWS with a single factor structure (Additional file 1: Appendix). The BSAWS includes the following domains used in the full scale: emotion regulation (items 22 and 27), reminiscence (items 18, 23 and 40), openness (item 34), experience (items 6 and 36) and humour (item 29). The newly proposed BSAWS scores in studies $1,2,3$ and 4 are $35.529(\mathrm{SD}=9.14), 36.610$ $(\mathrm{SD}=8.44), 37.704 \quad(\mathrm{SD}=7.66)$ and $37.780(\mathrm{SD}=9.04)$, respectively.

\section{Internal consistency and factorial validity}

Table 3 presents the descriptive statistics, including the mean, standardised deviation, skewness, kurtosis, corrected item-total correlations and Cronbach's alpha, if item deleted, for all nine items of the BSAWS based on the data from study 1 . The results show that the BSAWS demonstrates good internal consistency. The corrected item-to-total correlations for the BSAWS ranges from 0.349 to 0.619 and Cronbach's alpha is above the acceptable range, i.e., 0.808. The BSAWS is also significantly positively correlated $(r=0.912, p<0.001)$ with SAWS.

The results of the KMO and Bartlett's tests of sphericity for the nine-item BSAWS were $0.823\left(\chi^{2}=374.389\right.$, $p<.001)$, thus indicating appropriate scale construction. The EFA results showed that the factor loadings ranged from 0.477 to 0.738 and explained $40.453 \%$ of the total variance (Table 3$)$.

Table 3 Descriptive statistics and factor loadings from the exploratory factor analysis of BSAWS

\begin{tabular}{llllllll}
\hline Item & $\bar{x}$ & SD & sk & $k u$ & $r_{\text {it }}$ & $a_{\text {iid }}$ & $\lambda$ \\
\hline 6 & 4.222 & 1.742 & -0.805 & -0.635 & 0.368 & 0.807 & 0.477 \\
18 & 3.898 & 1.630 & -0.572 & -0.752 & 0.511 & 0.787 & 0.636 \\
22 & 4.331 & 1.571 & -0.905 & -0.143 & 0.582 & 0.779 & 0.707 \\
23 & 3.936 & 1.636 & -0.618 & -0.779 & 0.349 & 0.808 & 0.447 \\
27 & 3.828 & 1.594 & -0.513 & -0.728 & 0.505 & 0.788 & 0.643 \\
29 & 3.790 & 1.664 & -0.447 & -0.976 & 0.579 & 0.778 & 0.711 \\
34 & 3.955 & 1.499 & -0.663 & -0.404 & 0.619 & 0.775 & 0.738 \\
36 & 4.376 & 1.439 & -1.194 & 0.698 & 0.534 & 0.785 & 0.654 \\
40 & 3.191 & 1.769 & 0.086 & -1.365 & 0.504 & 0.788 & 0.646
\end{tabular}

$\overline{\mathrm{x}}$ mean, $S D$ standard deviation, sk skewness, $k u$ kurtosis, $r_{i t}$ corrected item-total correlations, $a_{i d}$ Cronbach's alpha, if item deleted; $\lambda$ factor loadings

\section{Convergent and concurrent validity}

The results from study 1 show the relationships between BSAWS and SAWS and the other construct-related scales suggested in the wisdom literature. Well-being as measured by the PWI has significant moderate positive relationships with SAWS $(r=0.363, p<0.001)$ and BSAWS $(r=0.347, p<0.001)$. The self-esteem scale also possesses a moderate positive relationship with the two scales. SAW and BSAWS are strongly correlated with the WDS, with $r=0.730(p<0.001)$ and $r=0.741(p<$ $0.001)$, respectively. The results also show a weak negative correlation between the scales and GDS, with $r=-0.290(p<0.001)$ for SAWS and $r=-0.345(p<$ 0.001 ) for BSAWS. The above findings have been replicated in the subsequent studies 2, 3 and 4 (Table 4). To sum up, the nine-item BSAWS is comparable with the full scale and possesses good convergent validity based on the results of Pearson's correlation coefficient.

\section{Content validity}

To further validate the content validity of BSAWS, CFA was implemented on the data collected from studies 2, 3 and 4 . The CFA results for BSAWS (Table 5 and Fig. 1) indicate good model fit, particularly the combined results across studies 2, 3 and 4, with $X^{2}(51.278) \quad / 27=1.90, \quad \mathrm{SRMR}=0.040, \mathrm{CFI}=$ 0.996, TLI $=0.995$ and RMSEA $=0.049$. Overall, the results indicate that the nine-item BSAWS has generally good fit for a unidimensional factor structure without any post hoc modifications.

\section{Discussion}

The proposed BSAWS possesses good psychometric properties and is comparable with its full-scale version. According to JD Webster, M Taylor and G Bates [19], 'the SAWS subscales [are] based upon input by a panel of wisdom experts' (p. 256). The results of this study show that the BSAWS supports the original five domains of wisdom advocated in the original SAWS, i.e., emotion, regulation, reminiscence, openness, experience and humour. Cronbach's alpha for the BSAWS is 0.808 , which is similar to the values ranging from 0.78 to 0.90 reported in the original SAWS studies [2, 23]. The nine-item shortened version of SAWS also possesses good convergent validity. The results show that SAWS and the BSAWS both hold identical correlational direction and magnitude with the other wellestablished measurements of well-being, self-esteem 
Table 4 Correlations between SAWS and BSAWS in relation to other construct-related scales

\begin{tabular}{llllllll}
\hline Scale & SAWS & BSAWS & SAWS & BSAWS & SAWS & BSAWS & $\begin{array}{l}\text { SAWS } \\
\text { Study } 4\end{array}$ \\
\hline PWI & Study 1 & & Study 2 & & BSAWS & $0.363^{* * *}$ \\
RSE & $0.340^{* * *}$ & $0.357^{* * *}$ & $0.469^{* * *}$ & $0.389^{* * *}$ & $0.617^{* * *}$ & $0.584^{* * *}$ & $0.530^{* * *}$ \\
WDS & $0.730^{* * *}$ & $0.741^{* * *}$ & $0.392^{* * *}$ & $0.410^{* * *}$ & $0.329^{* * *}$ & $0.280^{* * *}$ & $0.441^{* * *}$ \\
GDS & $-0.290^{* * *}$ & $-0.345^{* * *}$ & $-0.258^{* *}$ & $-0.240^{* *}$ & $-0.294^{* * *}$ & $-0.294^{* * *}$ & $-0.188^{* * *}$ \\
\hline
\end{tabular}

$P W I$ personal well-being index, RSE Rosenberg self-esteem, WDS wisdom development scale, GDS geriatric depression scale

${ }^{*} p<0.05$. ${ }^{* *} p<0.01$. ${ }^{* * *} p<0.001$

and depression. Both scales also have very strong and significant positive correlations $(r=0.912, p<0.001)$. The independent-sample t-test results show that no significant differences were observed in both scale scores on sex of the respondents. There were only weak significant correlation between the educational level $(r=0.294, p<0.001 ; r=-0.328, p<0.001)$ and age $(r=$ $0.292, p<0.001 ; r=-0.265, p<0.001)$ of the respondents in BSAWS and SAWS scores, respectively. These findings are aligned with the other wisdom constructs that focused on older adults [12].

This study contributes to the measurement of wisdom in the following ways. First, the shortened version of SAWS can help resolve disputes related to the complicated factor structure and dimensionality of the full version of SAWS. The original scale developer and the subsequent validation studies have generally failed to fully replicate the five latent factor structure of the 40 item scale $[2,18,23,33,34]$. For example, a recent study showed that some SAWS items did not load on any factor and that the openness dimension had a questionable Cronbach's alpha of 0.68 [18, 43, 80]. Consequently, some studies have attempted to shorten the scale by forcefully combining SAWS with other wisdom related constructs without using strict validation procedures to examine the psychometric properties of the revised scale [32, 34]. A validated abbreviated version of SAWS can

Table 5 Factor loadings and fit indices from the confirmatory factor analysis of BSAWS, by study (see Fig. 1 for the estimated model)

\begin{tabular}{|c|c|c|c|c|c|}
\hline \multirow[b]{2}{*}{ Factor/question } & & \multicolumn{4}{|l|}{ Study } \\
\hline & & 2 & 3 & 4 & Combo \\
\hline 6. I have made important decisions throughout my life. & $\lambda_{1}$ & 0.459 & 0.641 & 0.710 & 0.585 \\
\hline 18. Reviewing my past gives me a good perspective on my current concerns. & $\lambda_{2}$ & 0.775 & 0.749 & 0.692 & 0.732 \\
\hline 22. I can easily express my emotions without feeling like I am losing control of the situation. & $\lambda_{3}$ & 0.805 & 0.727 & 0.760 & 0.760 \\
\hline 23. I often recall the past to see if I have changed since then. & $\lambda_{4}$ & 0.506 & 0.528 & 0.576 & 0.538 \\
\hline 27. I am good at identifying subtle emotions in myself. & $\lambda_{5}$ & 0.668 & 0.678 & 0.830 & 0.721 \\
\hline 29. I often use humour to put other people at ease. & $\lambda_{6}$ & 0.622 & 0.582 & 0.849 & 0.680 \\
\hline 34. Now I know I can truly appreciate the little things in life. & $\lambda_{7}$ & 0.818 & 0.801 & 0.839 & 0.815 \\
\hline 36. I have learned valuable life lessons with others. & $\lambda_{8}$ & 0.643 & 0.699 & 0.789 & 0.705 \\
\hline 40. I often wonder about the mysteries of life and what lies beyond death. & $\lambda_{9}$ & 0.592 & 0.554 & 0.668 & 0.587 \\
\hline \multicolumn{6}{|l|}{ Model fit } \\
\hline$N$ & & 136 & 135 & 98 & 369 \\
\hline RMSEA & & 0.055 & 0.069 & 0.084 & 0.049 \\
\hline RMSEA $90 \%$ confidence interval & & $0.000-0.093$ & $0.029-0.105$ & $0.038-0.126$ & $0.028-0.070$ \\
\hline SRMR & & 0.059 & 0.057 & 0.064 & 0.040 \\
\hline$x^{2}(d f=27)$ & & 37.984 & 44.441 & 45.609 & 51.278 \\
\hline$x^{2} / d f$ & & 1.41 & 1.65 & 1.69 & 1.90 \\
\hline $\mathrm{CFI}$ & & 0.995 & 0.992 & 0.994 & 0.996 \\
\hline TLI & & 0.993 & 0.989 & 0.993 & 0.995 \\
\hline
\end{tabular}

RMSEA root mean square error of approximation, SRMR standardised root mean residual, CFI comparative fit index, TLI Tucker Lewis index, Study 2 initial study plus 1 month, Study 3 initial study plus 2 months, Study 4 initial study plus 8 months, Combo combined across the three studies 


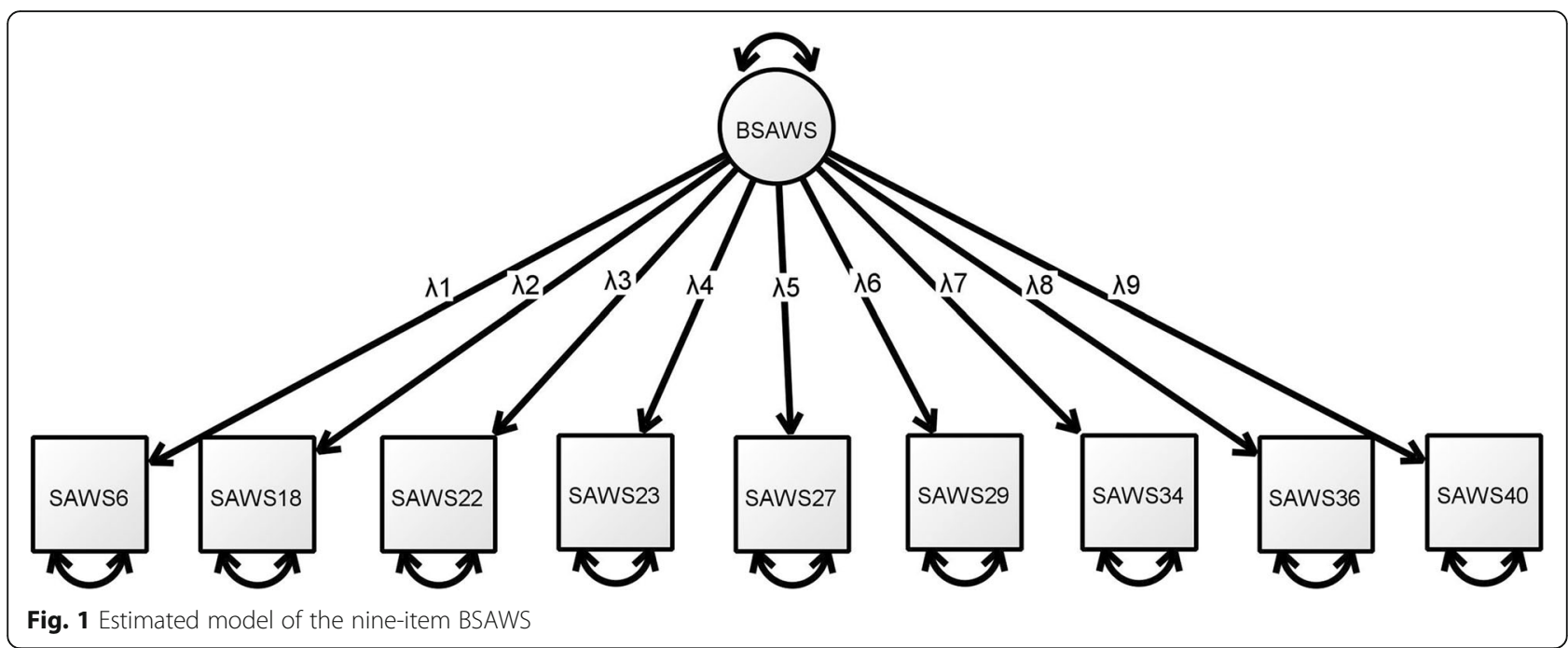

serve as a useful instrument for designing future studies related to wisdom among older adults and other populations.

This study also provides empirical evidence to support the factor structure of the BSAWS using CFA. Numerous SAWS related studies have used only EFA to evaluate the factorial validity of the scale, without verifying the construct validity with CFA [2, 18, 33]. The only SAWS validation study to use CFA was based on five sub-scales, which served as the latent factors for estimating the loadings on the wisdom construct rather than evaluating all 40 items. The results failed to meet the criteria for adequate model fit, with $\mathrm{CFI}=0.947$ and RMSEA $=0.107$ [23]. The CFA results of Models 1 and 2 (Table 2) in this study managed to replicate the problem of analysing the 40 items using a five latent factor structure. The results showed that none of the models were considered to have a good fit. However, the CFA results for the newly proposed nine-item BSAWS fulfilled all of the stringent criteria for determining good model fit in the structural equation modelling literature [50, 51, 55].

The procedure for developing the BSAWS strictly adhered to the recognised scale development and validation principles to avoid the potential problem of overfitting $[43,81]$. The sample from study $1(n=156)$ was used to conduct EFA to identify the factor structure of BSAWS. The study $2(n=136), 3(n=135)$ and $4(n=$ 98) samples were then used to verify the scale's content validity using CFA. In addition, various psychometric evaluation tools were used to examine the internal consistency and convergent validity of the nine-item BSAWS. In short, the BSAWS was found to possess excellent psychometric properties.

This study has the following potential limitations. First, the small sample size may limit the reliability of the results. This limitation may account for why the
CFA results in study $4(n=98)$ only yielded a marginally adequate RMSEA value. Some scholars suggested that a minimum sample size $(N=100)$ is preferred for CFA, but simulation studies suggested that the model $(N>50)$ with more items $(>6)$ per factor may overcome this limitation [82-84]. The research team had difficulty recruiting significant numbers of respondents from the older adult service centres in Hong Kong. However, the longitudinal repeated measures design used in this study may have compensated for this limitation. The second potential limitation is related to the demographic background of the respondents. Specifically, the results based on Chinese older adults in Hong Kong may have limited generalisability. Lastly, the standalone 9-item scale may need further validation, as the participants may potentially affected by responding to the other 31 items in the scale. Thus, further research is needed to replicate our findings or apply the BSAWS in different cultural contexts to verify this refinement of SAWS. With the abbreviated version of SAWS, it enables researchers to further examine the queries related to wisdom and other psychosocial outcomes, such as its relationship with hedonic and eudaimonia well-being [10, 85-87] in future research projects.

\section{Conclusions}

This study developed and validated an abbreviated nineitem version of SAWS. The results suggest that the BSAWS possesses good internal consistency, acceptable model fit for a CFA and is comparable with its 40-item full version. The newly developed scale can provide an efficient and valid assessment of wisdom for older adults. This abbreviated standardised wisdom measure may encourage researchers and practitioners to conduct epidemiological surveys to evaluate the effectiveness of 
interventions in a clinical setting. However, future work is needed to confirm the psychometric properties of the scale in larger or more generalisable samples.

\section{Supplementary information}

Supplementary information accompanies this paper at https://doi.org/10. 1186/s12877-020-1456-9.

Additional file 1: Appendix. Factor structure and dimensionality of SAWS and BSAWS.

\section{Abbreviations}

BSAWS: Brief self-assessed wisdom scale; CFI: Comparative fit index; ER: Emotion regulation; EXP: Experience; GDS: Geriatric depression scale; HU: Humour; OP: Openness; PWl: Personal wellbeing index; RE: Reminiscence; RMSEA: Root mean square error of approximation; RSE: Rosenberg selfesteem; SAWS: Self-assessed wisdom scale; SRMR: Standardized root mean residual; TLI: Tucker Lewis Index; WDS: Dimensions of the wisdom development scale

\section{Acknowledgements}

None.

\section{Authors' contributions}

SF contributed in study concept, design, data analysis, data interpretation and writing of the manuscript. EC and CC were responsible for the funding acquisition, project administration and data collection. All authors reviewed the manuscript critically and approved the final version.

\section{Funding}

The project is funded by the General Research Fund provided by the Research Grant Council, Hong Kong (grant number: 9042296). The funding body had no influence on the content of the paper and the publication process.

\section{Availability of data and materials}

The datasets used and analysed during the current study are available from Esther Oi-wah Chow on reasonable request.

\section{Ethics approval and consent to participate}

This study was approved by the research ethical committee of the City University of Hong Kong. Its procedure was in compliance with the Declaration of Helsinki guidelines. All of the participants gave written consent prior to the study.

\section{Consent for publication}

Not applicable.

\section{Competing interests}

The authors declare that they have no competing interests.

Received: 7 June 2019 Accepted: 3 February 2020

Published online: 12 February 2020

\section{References}

1. Ferrari M, Weststrate NM. The Scientific Study of Personal Wisdom. In: Ferrari M, Weststrate NM, editors. The Scientific Study of Personal Wisdom: From Contemplative Traditions to Neuroscience. Dordrecht: Springer Netherlands; 2013. p. 325-41

2. Webster JD. An exploratory analysis of a self-assessed wisdom scale. J Adult Dev. 2003;10(1):13-22.

3. Bangen KJ, Meeks TW, Jeste DV. Defining and assessing wisdom: a review of the literature. Am J Geriatr Psychiatr. 2013;21(12):1254-66.

4. Seligman MEP, Csikszentmihalyi M. Positive psychology - an introduction. Am Psychol. 2000;55(1):5-14.

5. Brown SC, Greene JA. The wisdom development scale: translating the conceptual to the concrete. J Coll Stud Dev. 2006;47(1):1-19.
6. Baltes PB, Staudinger UM. Wisdom - a metaheuristic (pragmatic) to orchestrate mind and virtue toward excellence. Am Psychol. 2000;55(1): 122-35

7. Staudinger UM, Pasupathi M. Correlates of wisdom-related performance in adolescence and adulthood: age-graded differences in "paths" toward desirable development. J Res Adolesc. 2003;13(3):239-68.

8. Zacher H, McKenna B, Rooney D, Gold S. Wisdom in the military context. Milit Psychol. 2015;27(3):142-54.

9. Hu CS, Ferrari M, Wang QD, Woodruff E. Thin-Slice Measurement of Wisdom. Front Psychol. 2017;8:10

10. Mickler C, Staudinger UM. Personal wisdom: validation and age-related differences of a performance measure. Psychol Aging. 2008;23(4):787-99.

11. Wink $P$, Staudinger UM. Wisdom and psychosocial functioning in later life. $J$ Pers. 2016;84(3):306-18.

12. Ardelt M. Empirical assessment of a three-dimensional wisdom scale. Res Aging. 2003;25(3):275-324.

13. Wink P, Helson R. Practical and transcendent wisdom: their nature and some longitudinal findings. J Adult Dev. 1997;4(1):1-15.

14. Brown SC. Learning across the campus: how college facilitates the development of wisdom. J Coll Stud Dev. 2004;45(2):134-48.

15. Glück J, König S, Naschenweng K, Redzanowski U, Dorner-Hörig L, Strasser I, Wiedermann W. How to measure wisdom: content, reliability, and validity of five measures. Front Psychol. 2013;4(405):1-13. https://doi.org/10.3389/fpsyg. 2013.00405

16. Glück J. Measuring wisdom: existing approaches, continuing challenges, and new developments. J Gerontol B Psychol Sci Soc Sci. 2017;73(8):1393-403.

17. Ardelt M. The measurement of wisdom: a commentary on Taylor, Bates, and Webster's comparison of the SAWS and 3D-WS. Exp Aging Res. 2011;37(2): 241-55.

18. Taylor M, Bates G, Webster JD. Comparing the psychometric properties of two measures of wisdom: predicting forgiveness and psychological well-being with the self-assessed wisdom scale (SAWS) and the threedimensional wisdom scale (3D-WS). Exp Aging Res. 2011;37(2):129-41.

19. Webster JD, Taylor M, Bates G. Conceptualizing and measuring wisdom: a reply to Ardelt reply. Exp Aging Res. 2011;37(2):256-9.

20. Bassett CL. Understanding and Teaching Practical Widsom. In: Tisdell EJ, Swartz AL, editors. Adult Education and the Pursuit of Wisdom. New York: Wiley; 2011. p. 35-44.

21. Greene JA, Brown SC. The wisdom development scale: further validity investigations. Int J Aging Human Dev. 2009;68(4):289-320.

22. Chen L-M, Wu P-J, Cheng Y-Y, Hsueh H-I. A qualitative inquiry of wisdom development: Educators' perspectives. Int J Aging Hum Dev. 2011;72(3):171-87.

23. Webster JD. Measuring the character strength of wisdom. Int J Aging Hum Dev. 2007:65(2):163-83.

24. Thomas ML, Bangen KJ, Ardelt M, Jeste DV. Development of a 12-item abbreviated three-dimensional wisdom scale (3D-WS-12): item selection and psychometric properties. Assessment. 2017:24(1):71-82

25. Bang HY, Zhou YC. The function of wisdom dimensions in ego-identity development among Chinese university students. Int J Psychol. 2014;49(6): 434-45.

26. Li HQ, Wang FY. A three-dimensional model of the wise personality: a free classification approach. Soc Behav Pers. 2017;45(11):1879-88.

27. Webster JD, Weststrate NM, Ferrari M, Munroe M, Pierce TW. Wisdom and meaning in emerging adulthood. Emerg Adulthood. 2018;6(2):118-36.

28. Webster JD. Wisdom and positive psychosocial values in young adulthood. J Adult Dev. 2010;17(2):70-80.

29. Webster JD, Westerhof GJ, Bohlmeijer ET. Wisdom and mental health across the lifespan. J Gerontol Ser B-Psychol Sci Soc Sci. 2014;69(2):209-18.

30. Webster JD, Bohlmeijer ET, Westerhof GJ. Time to flourish: the relationship of temporal perspective to well-being and wisdom across adulthood. Aging Ment Health. 2014;18(8):1046-56.

31. Webster JD, Deng XC. Paths from trauma to intrapersonal strength: worldview, posttraumatic growth, and wisdom. J Loss Trauma. 2015;20(3):253-66

32. Cheung C, Chow EO. Contribution of wisdom to well-being in Chinese older adults. Appl Res Qual Life. 2019. https://doi.org/10.1007/s11482-019-9712-X.

33. Alves $\mathrm{P}$, Morgado L, Bd O. Wisdom assessment: Portuguese adaptation of the self-assessed wisdom scale - SAWS - by Jeffrey Webster. Psychologica. 2014:57(1):39-57.

34. Urrutia A, de Espanes GM, Ferrari C, Borgna G, Alderete AM, Villar F. Development and validation of the brief scale of self-assessed wisdom (EBAS) in Argentinian older adults. Univ Psychol. 2016;15(2):11. 
35. Dunlap WP, Cortina JM, Vaslow JB, Burke MJ. Meta-analysis of experiments with matched groups or repeated measures designs. Psychol Methods. 1996;1(2):170-7.

36. Obrien RG, Kaiser MK. Manova method for analyzing repeated measures designs - an extensive primer. Psychol Bull. 1985;97(2):316-33.

37. Ellis MV. Repeated measures designs. Couns Psychol. 1999;27(4):552-78.

38. Brislin RW. Back-translation for cross-cultural research. J Cross-Cult Psychol. 1970;1(3):185-216.

39. Chang AM, Chau JPC, Holroyd E. Translation of questionnaires and issues of equivalence. J Adv Nurs. 1999:29(2):316-22.

40. Cha ES, Kim KH, Erlen JA. Translation of scales in cross-cultural research: issues and techniques. J Adv Nurs. 2007:58(4):386-95.

41. Brown TA. Confirmatory factor analysis for applied research. 2nd ed. New York: Guilford Publications; 2014.

42. Jöreskog KG. A general approach to confirmatory maximum likelihood factor analysis. Psychometrika. 1969;34(2):183-202.

43. Loewenthal KM. An introduction to psychological tests and scales. 2nd ed. Philadelphia: Psychology Press; 2001.

44. DiStefano C, Morgan GB. A comparison of diagonal weighted least squares robust estimation techniques for ordinal data. Struct Equ Model Multidiscip J. 2014:21(3):425-38.

45. Li C-H. Confirmatory factor analysis with ordinal data: comparing robust maximum likelihood and diagonally weighted least squares. Behav Res Methods. 2016;48(3):936-49.

46. Lionetti F, Keijsers L, Dellagiulia A, Pastore M. Evidence of factorial validity of parental knowledge, control and solicitation, and adolescent disclosure scales: when the ordered nature of Likert scales matters. Front Psychol. 2016;7:941.

47. Fung S. Psychometric Evaluation of the Warwick-Edinburgh Mental Wellbeing Scale (WEMWBS) with Chinese University Students. Health Qual Life Outcomes. 2019;17:46.

48. Fung S. Cross-cultural validation of the social media disorder scale. Psycho Res Behav Manag. 2019;12:683-90.

49. Fung S, Kong CYW, Huang Q. Evaluating the Dimensionality and Psychometric Properties of the Brief Self-Control Scale Amongst Chinese University Students. Front Psychol. 2020;10(2903):1-10. https://doi.org/10. 3389/fpsyg.2019.02903.

50. Hair JF. Multivariate data analysis. 7th ed. Upper Saddle River: Prentice Hall; 2010.

51. Hu L, Bentler PM. Cutoff criteria for fit indexes in covariance structure analysis: conventional criteria versus new alternatives. Struct Equ Model Multidiscip J. 1999;6(1):1-55.

52. Schreiber JB, Nora A, Stage FK, Barlow EA, King J. Reporting structural equation modeling and confirmatory factor analysis results: a review. J Educ Res. 2006;99(6):323-38

53. Bentler PM, Bonett DG. Significance tests and goodness of fit in the analysis of covariance structures. Psychol Bull. 1980;88(3):588-606.

54. Byrne BM. Structural equation modeling with LISREL, PRELIS, and SIMPLIS : basic concepts, applications, and programming. Mahwah: L. Erlbaum Associates; 1998.

55. Kline RB. Principles and practice of structural equation modeling. 2nd ed. New York: Guilford Press; 2005

56. Satorra A, Bentler PM. A scaled difference chi-square test statistic for moment structure analysis. Psychometrika. 2001;66(4):507-14.

57. Jennrich Rl, Sampson PF. Rotation for simple loadings. Psychometrika. 1966; 31(3):313-23.

58. Field AP. Discovering statistics using IBM SPSS statistics. 5th ed. Los Angeles: SAGE Publications; 2018

59. Cronbach $L$ J. Coefficient alpha and the internal structure of tests. Psychometrika. 1951;16(3):297-334.

60. Tabachnick BG. Using multivariate statistics. 6th ed. Boston: Pearson Education; 2013

61. Ardelt M. Disentangling the relations between wisdom and different types of well-being in old age: findings from a short-term longitudinal study. Happiness Stud. 2016;17(5):1963-84

62. Etezadi S, Pushkar D. Why are wise people happier? An explanatory model of wisdom and emotional well-being in older adults. J Happiness Stud. 2013;14(3):929-50

63. Hultsch DF, MacDonald SWS, Hunter MA, Maitland SB, Dixon RA Sampling and generalisability in developmental research: comparison of random and convenience samples of older adults. Int J Behav Dev. 2002;26(4):345-59.

64. Clark PG. Quality-of-life, values, and teamwork in geriatric care - do we communicate what we mean. Gerontologist. 1995;35(3):402-11.

65. Day JM. Religion, spirituality, and positive psychology in adulthood: a developmental view. J Adult Dev. 2010;17(4):215-29.

66. IWG: Personal Wellbeing Index: 5. In. Melbourne: Australia Center on Quality of Life, Deakin University; 2013.

67. Chen ZH, Davey G. Subjective quality of life in Zhuhai City, South China: a public survey using the international wellbeing index. Soc Indic Res. 2009; 91(2):243-58.

68. Rosenberg M, Schooler C, Schoenbach C. Self-esteem and adolescent problems: modeling reciprocal effects. Am Sociol Rev. 1989;54(6):1004-18.

69. Wu Y, Zuo B, Wen FF, Yan L. Rosenberg self-esteem scale: method effects, factorial structure and scale invariance across migrant child and urban child populations in China. J Pers Assess. 2017;99(1):83-93.

70. Chou KL. Assessing shyness in Chinese older adults. Aging Ment Health 2005;9(5):456-60.

71. Zhang X, Chen X, Ran GM, Ma YX. Adult children's support and self-esteem as mediators in the relationship between attachment and subjective wellbeing in older adults. Personal Individ Differ. 2016;97:229-33.

72. Zhao L, Zhang $X$, Ran GM. Positive coping style as a mediator between older adults' self-esteem and loneliness. Soc Behav Pers. 2017;45(10): $1619-28$

73. Zhang JX, Peng JX, Gao P, Huang H, Cao YF, Zheng LL, Miao DM. Relationship between meaning in life and death anxiety in the elderly: selfesteem as a mediator. BMC Geriatr. 2019;19(1):8.

74. Khalaila R. Depression statuses and related predictors in later life: a 10-year follow-up study in Israel. Eur J Ageing. 2016;13(4):311-21.

75. Blazer DG, Hybels CF. Origins of depression in later life. Psychol Med. 2005: 35(9):1241-52.

76. Yesavage JA, Brink TL, Rose TL, Lum O, Huang V, Adey M, Leirer VO. Development and validation of a geriatric depression screening scale - a preliminary-report. J Psychiatr Res. 1983;17(1):37-49.

77. Dow B, Lin X, Pachana NA, Bryant C, LoGiudice D, Goh A MY, Haralambous B. Reliability, concurrent validity, and cultural adaptation of the geriatric depression scale and the geriatric anxiety inventory for detecting depression and anxiety symptoms among older Chinese immigrants: an Australian study. Int Psychogeriatr. 2017;30(5):735-48.

78. He J, Zhong X, Yao S. Factor structure of the geriatric depression scale and measurement invariance across gender among Chinese elders. J Affect Disord. 2018:238:136-41.

79. Rosseel Y. lavaan: An R Package for Structural Equation Modeling. J Stat Softw. 2012:48(2):36.

80. Nunnally JC, Bernstein IH. Psychometric theory. 3rd ed. New York: McGrawHill; 1994

81. Fokkema M, Greiff S. How performing PCA and CFA on the same data equals trouble Overfitting in the assessment of internal structure and some editorial thoughts on it. Eur J Psychol Assess. 2017;33(6):399-402.

82. Marsh HW, Hau KT, Balla JR, Grayson D. Is more ever too much? The number of indicators per factor in confirmatory factor analysis. Multivariate Behav Res. 1998;33(2):181-220.

83. Velicer WF, Fava JL. Effects of variable and subject sampling on factor pattern recovery. Psychol Methods. 1998;3(2):231-51.

84. Rhemtulla M, Brosseau-Liard PE, Savalei V. When can categorical variables be treated as continuous? A comparison of robust continuous and categorical SEM estimation methods under suboptimal conditions. Psychol Methods. 2012;17(3):354-73.

85. Hu CS, Huang J, Ferrari M, Wang Q, Xie D, Zhang H. Sadder but wiser: emotional reactions and wisdom in a simulated suicide intervention. Int J Psychol. 2018:54(6):791-9.

86. Kunzmann U, Baltes PB. Wisdom-related knowledge: affective, motivational, and interpersonal correlates. Personal Soc Psychol Bull. 2003;29(9):1104-19.

87. Waterman AS. 2 conceptions of happiness: contrasts of personal expressiveness (eudaimonia) and hedonic enjoyment. J Pers Soc Psychol. 1993:64(4):678-91.

\section{Publisher's Note}

Springer Nature remains neutral with regard to jurisdictional claims in published maps and institutional affiliations. 